\title{
Invertebrate and vertebrate models in aging research
}

\author{
Manoj Kumar Chaudhary, Syed Ibrahim Rizvi
}

\begin{abstract}
Therapeutic interventions that can delay age associated diseases and ensure a longer health-span is a major goal of aging research. Consequent to understanding that aging is a modifiable trait, a large number of studies are currently being undertaken to elucidate the mechanism(s) of the aging process. Research on human aging and longevity is difficult, due to longer time frame, ethical concerns and environmental variables. Most of the present day understanding about the aging process comes through studies conducted on model organisms. These provide suitable platforms for understanding underlying mechanism(s) which control aging and have led to major discoveries that emphasize the evolutionarily conserved molecular pathways as key players that respond to extra and intracellular signals. This is a review of various invertebrate and vertebrate models including yeast, Drosophila, C. elegans, rodents, naked mole rat, and birds, currently used in aging research with emphasis on how well they can mimic aging in higher animals and humans.
\end{abstract}

Key words: aging, longevity, model organisms

Received: July 2, 2018; Accepted with revision: February 6, 2019; Available online: March 5, 2019 https://doi.org/10.5507/bp.2019.003

Department of Biochemistry, University of Allahabad, Allahabad-211002, India

Corresponding author: Syed Ibrahim Rizvi, e-mail: sirizvi@gmail.com

\section{INTRODUCTION}

A major part of biological research on aging has largely focused on healthspan and lifespan extension. The reduced morbidity and unprecedented increase in human life expectancy were major breakthroughs of the past century which was achieved due to elimination of fatal infectious diseases through development of antibiotics and vaccines along with improved health care systems and better hygiene. However, despite achievements in lifespan extension, the precise underlying mechanism(s) which control aging remain largely elusive ${ }^{1,2}$.

Although many theories suggest the aging process was a function of natural selection in favor of evolutionary benefits, the data from studies of model organisms have established that the rate of aging exhibits plasticity and that the rate of oxygen free radical generation during cellular respiration determines the rate of aging ${ }^{3}$. It has been suggested that oxidative stress is the casual factor in the loss of telomere which plays a major role in the longevity of a species ${ }^{4,5}$. Besides these, knowledge from studies in yeast, worms and flies have revealed several evolutionary conserved genetic pathways and biochemical processes through which oxidative stress influences the rate of aging ${ }^{6}$. In particular, these responses are mediated by nutrient and stress sensors which respond to numerous environmental and physiological signals. The best known of these signals is caloric restriction (CR), which is known to extend the lifespan in many species, from yeast to primates ${ }^{7}$. Besides these, certain organisms like hydra and lobsters bear exceptionally high proliferative capacity and thus retain tissue integrity or reproductive capacity with increasing chronological time thereby escaping aging phenomena ${ }^{8,9}$.
Using a human model to study aging is complicated by several factors including longer time frame, ethical concerns and the influence of environmental factors. Aging research therefore relies heavily on model organisms which have significantly contributed to our present knowledge in dissecting evolutionary conserved pathways known to play important roles in human aging.

\section{Yeast as a model of aging}

Saccharomyces cerevisiae (S. cerevisiae), commonly known as brewer's yeast, is a unicellular eukaryotic fungi frequently used to study basic eukaryotic cellular processes including DNA repair and cell cycle, intracellular trafficking, and protein folding regulation ${ }^{10}$. In recent years, yeast has emerged as a powerful tool to study the aging mechanism(s) of eukaryotic organism. Due to its genetic simplicity of having only 6000 genes $^{11}$, very small propagation time of 1.5-3 h, uncomplicated genetic approach, and easy accessibility to Saccharomyces Genome Database, yeast is used in aging research ${ }^{12}$.

Two distinct patterns of aging are evident in yeast, the replicative life span (RLS) and chronological lifespan (CLS). The RLS refers to number of times a mother cell undergoes a mitotic cell division to produce virgin daughter cells and is marked by gradual loss of its reproductive capabilities ${ }^{13}$. The replicative life span of these organism is analogous to replicative cellular senescence observed in dividing cells of higher eukaryotes, such as stem cells, fibroblasts and lymphocytes, which show cessation of population growth when maintained in culture $\mathrm{r}^{11,14}$. The CLS is defined as the time through which the cells retain viability in their post-replicative state. Yeast chronological aging corresponds to the aging of non-dividing mammalian cells such as neurons ${ }^{15}$. 
Previous studies have shown that aging exhibits plasticity and an array of genetic and non-genetic factors influence the rate of aging. One of the most extensively studied interventions known to delay aging in wide range of species is $\mathrm{CR}$ which equally influence the rate of aging in yeast. In response to reduced concentration of glucose in the culture medium, the replicative life span of yeast is reported to be extended by 20 to $40 \%$ (ref. ${ }^{16,17}$ ). CR in yeast has been reported to affect various nutrient-responsive signaling pathways including target of rapamycin (TOR), protein kinase A (PKA), and Sch9 kinases ${ }^{18}$. These highly conserved pathways coordinate a number of cellular phenomena including stress responses, protein turnover, cell growth, and ribosome biogenesis. Decreased activity of TOR signaling pathway is an important mediator of both replicative as well as chronological life span and mutations leading to down regulation of this pathway is known to extend both replicative as well as chronological life span in yeast $\mathrm{t}^{18,19}$. Interestingly, decrease in TOR activity has also been reported to the increase life span in both worms and flies, which provides evidence for an evolutionarily conserved role for TOR as a regulator of aging ${ }^{20}$. Apart from this, the mutations that decrease the activity of the nutrientsensitive kinase Sch9 or adenylate cyclase, an activator of the cyclic AMP-dependent protein kinase, also increases CLS (ref. ${ }^{21}$ ). These proteins are normally activated in the presence of substantial amounts of nutrients, especially glucose, and Sch9 and PKA are thought to signal parallel pathways that increase glycolysis, ribosome biogenesis, growth, and cell cycle progression, and to inhibit stress response pathways ${ }^{22,23}$.

Several pathways involved in age associated degenerative diseases in higher animals are well conserved in yeast including impaired mitochondrial function, transcriptional dysregulation, vesicular trafficking defects and loss of proteasomal function as well as protein folding and degradation, autophagy, and apoptosis ${ }^{24}$. Genetic studies confirm about $17 \%$ of the $S$. cerevisiae genes (approximately 1000 genes) are members of the orthologous gene families associated with various human diseases ${ }^{25}$. The role of reactive oxygen species (ROS) as a contributor to aging has been well established ${ }^{26,3}$. Yeast shows similarities in oxidative stress response to mammalian cells in terms of their production sites and antioxidant defense mechanisms ${ }^{27}$. The importance of yeast as a model in research on Huntington disease (HD) is recognised. It has helped in the elucidation of mechanistic features of mHTT cytotoxicity and has established the potential of yeast as a platform for screening for pharmacological agents against $\mathrm{HD}\left(\right.$ ref. $\left.^{28}\right)$.

\section{Drosophila as a model of aging}

Drosophila melanogaster (D. melanogaster), commonly known as fruit or vinegar flies, has a long history of use as a model organism which dates back to the early 1900s when Morgan laboratory at Columbia University introduced it for genetic studies ${ }^{29}$. It is now a favorite model organism for geneticists, because of its relatively short lifespan of about 60-80 days and a generation time of
9-10 days at controlled temperature $\left(25^{\circ} \mathrm{C}\right)$ which allows easy breeding ${ }^{6,30}$.

The $D$. melanogaster genome has been fully sequenced with intact genome size of about $180 \mathrm{Mb}$ including approximately $120 \mathrm{Mb}$ of euchromatin and $60 \mathrm{Mb}$ of heterochromatin. The size of annotated genome sequence of this organism constitute only $5 \%$ of the size of typical mammalian genome, however they conserve most of the gene families and pathways expressed in mammals ${ }^{31,32}$. Apart from this, D. melanogaster is also known to express approximately $77 \%$ of the genes involved in human diseases including those observed for Alzheimer disease (AD) such as amyloid precursor protein, presenilin and tau protein $^{30}$ and their genome shows least genetic redundancy, thus providing a suitable model to study gene function ${ }^{33}$.

Drosophila exhibits gender specific difference in lifespan. Although, the exact mechanism(s) are still not fully understood, asymmetric inheritance of mitochondrial genomes, hormonal and metabolic differences, and maternal effects may be the contributing factors ${ }^{34}$. Thus both male and female populations are required to be studied separately.

Drosophila is morphologically different with reference to mammals, yet they share significant anatomical and physiological features. They have evolved assemblies which show functional similarities with mammalian tissues such as fat bodies which are considered equivalent to the mammalian adipose tissue and liver ${ }^{35}$. In addition to this, Drosophila also exhibits functional similarity with mammals with reference to nervous system defects. The shaker phenotype is observed in flies due to mutation of Sh (shaker) gene. This gene encodes a voltage-sensitive potassium channel in the nervous system and is the functional homologue of human KCNA3 gene which mediates the voltage-dependent potassium ion permeability of excitable membranes through expression of potassium voltage-gated channel subfamily. Mutation in this gene causes multiple sclerosis in human with features similar to the shaker phenotype ${ }^{36}$.

Drosophila actively responds to environmental factors such as nutritional status, oxidative stress and the factors promoting inflammation ${ }^{37}$. The homozygous mutant of Drosophila involving insulin receptor substrate, Chico, is known to exhibit life span increase of approximately $50 \%$, which explains the importance of insulin-like growth factor signaling pathway ${ }^{38}$. In addition to this, inhibition of mTORC signalling pathway in Drosophila through mTOR mutation, rapamycin administration or mutation of S6K (the fly homologue of yeast Sch9) significantly lengthens the lifespan ${ }^{39}$. It is worth mentioning that a recent report has provided new insight into the effect of diet and gene expression on metabolism which is expected to clarify link between metabolism and lifespan/aging ${ }^{40}$. The importance of Drosophila melanogaster, as a model for aging and circadian interactions has recently been highlighted ${ }^{41}$. The findings are expected to facilitate the rapid advancement of research in this area and provide mechanistic insights for targeted investigations in mammals.

Conventionally, oxidative stress has been anticipated as a major contributor to aging and age related diseases. 
Drosophila has been effectively used as a model to establish the role of oxidative stress in aging. Studies have demonstrated the age-dependent increased levels of oxidized bio-molecules such as 8-oxo-guanine and protein carbonyls ${ }^{42}$. Besides this, Drosophila has also been effectively modeled to study immune senescence and inflammatory responses in aging and age related diseases ${ }^{43,44}$.

\section{Caenorhabditis elegans ( $C$. elegans) as a model of aging}

C. elegans as model organism for biological study was first introduced by Brenner in $1960 \mathrm{~s}^{45}$. The landmark history of aging biology was established with elucidation of genes responsible for modulation of lifespan. The identified gene in $C$. elegans affecting the lifespan was age-1 that encoded phosphatidyl inositol 3-kinase ${ }^{46}$. C. elegans is an aging model of preference for gerontological studies because it offers several advantages including shorter life span of few weeks in cultured medium at $20{ }^{\circ} \mathrm{C}$ with a completely sequenced and annotated genome ${ }^{47}$.

The development of RNA interference and availability of RNA-mediated interference library, comprising approximately $80 \%$ of the genes in the genome, has contributed much to genomic study of functional genes in $C$. elegans including those regulating the aging process ${ }^{48,49}$. Additionally, this organism exhibits several aging features including sluggish movement particularly due to muscle degeneration, accumulation of lipofucin pigment, and presence of vacuole like structure ${ }^{50}$. In addition to this, age-dependent increase in oxidized proteins are also reported $^{51}$. They also respond to adverse environmental conditions including nutritional deficiency or high population density. In response to such hazards, the worms activate an alternative developmental program that leads to formation of the highly stress-resistant dauer larvae ${ }^{52}$.

In addition to environmental factors, genetic factors also play important roles in the regulation of the life span of C. elegans ${ }^{53}$. Insulin-like growth factor (IGF)-1 signaling (IIS) pathway is known to regulate aging and longevity in many organisms, ranging from simple invertebrates to mammals ${ }^{54}$. In this organism, many components of the IIS pathway are evolutionarily conserved. Specifically, daf-2 and age-1 encode the nematode's sole insulin/IGF-1 receptor and phosphatidylinositol-3-OH kinase respectively, which are two key upstream components of IIS pathway ${ }^{55}$. Besides these, C. elegans also exhibit other well conserved genetic pathways including the AMPK pathway, the TOR pathway and SREBP pathway which is regulator of lipid homeostasis $^{56,57}$.

\section{Rodents as a model of aging}

Rodents are major laboratory animals and have contributed much in the progress of biomedical research. Mice and rats find preference in aging research because of their small size, fast reproduction rate, easy maintenance and average short life span of 2 years for mice and 3 years for rats ${ }^{58,59}$. Moreover, they are mammals and exhibit close proximity to humans with reference to their physiology and cellular functions ${ }^{60}$.

\section{Mice (Mus musculus)}

Mice (Mus musculus) are a commonly used model to study the biological process of aging. The immunological and endocrine responses as well as digestive and musculoskeletal system of mice show functional and structural resemblance to humans ${ }^{61,62}$. Apart from this, mice have also been modeled to study cardiac function and age-related changes in the liver. However, in comparison to the human brain, the mice brain is less complex, yet they show the functional similarities at molecular and cellular level ${ }^{63}$. Inbred mouse strains are preferred because they maintain genetic homogeneity. The C57BL/6 mice strain is most popularly used in aging studies and bears short lifespan of approximately 2 years ${ }^{64}$. The choice for these strains provide added benefits as they have defined genomes, stable phenotypes, and freely available data from published studies and other databases such as mouse genome informatics and mouse phenome database ${ }^{65,66}$. Premature loss of vision or hearing capacity is an important marker of aging in the inbred strain ${ }^{67}$. The inbred mice, however show limited pathologies, for example C57BL/6 mice are vulnerable to metabolic dysregulation and show high incidence of lymphoma ${ }^{68}$. Due to genetic homogeneity, the inbred strains do not represent the human population. Contrary to this, the out bread strains are comparatively long lived and show heterosis. These are genetically undefined but exhibit high degree of disease resistance and closely represent the human population. It has been shown that rapamycin fed both early and late in life extends life span in genetically heterogeneous mice ${ }^{69}$. A recent study on mouse model of aging has been instrumental in providing proof-of-principle that interventions aimed at rejuvenating stem cells are among the most effective strategies to modulate longevity and healthspan ${ }^{70}$.

\section{Rats (Rattus norvegicus domesticus)}

Apart from mice, the rats have also been extensively used in the laboratory for age-related diseases including cardiovascular disease, neurological disorders, neurobehavioral studies, cancer susceptibility, and renal disease, as well as for behavioral studies of cognition. The inbred rat strain such as Fischer 344 (F344) rats and other genetically defined (F1 hybrids) are frequently used rat models used in aging research. Three different breed, the F344, Brown-Norway (BN), and F1 hybrid of F344 X BN strains are available as model of study under National Institute on Aging ${ }^{64}$.

Much of the excitement in recent aging research has come from discoveries that aging can be postponed in mice or rats. These rodents respond to CR and demonstrate lifespan extension like worm and flies. The lifespan extension effect of CR is assumed to involve mTORC1 pathway and possibly also the sirtuins ${ }^{71}$. The growing interest on aging studies in rodents has been stimulated in recent years probably by the sequencing of mouse and human genomes. This has provided an added advantage to model most of the human genetic diseases by altering equivalent genes in these small animals. Through targeted genetic manipulation, several genetic lines of mice have been produced that model diseases such as Alzheimer's 
disease, Werner's syndrome (premature aging), diabetes mellitus, atherosclerosis, immune dysfunctions, oxidative stress, musculoskeletal disorders, and other medical conditions associated with aging ${ }^{72-74}$.

\section{Use of naked mole rats in aging research}

Naked mole rats are one of the most interesting rodent species with reference to gerontological studies, particularly because they have an exceptionally long lifespan of more than 30 years when compared to other common laboratory rodents with a maximum life span of 4 years ${ }^{75}$. These rats do not follow the rate of living hypothesis rule and usually survive five times longer than expected based on their size ${ }^{76}$. One of the most interesting facts is that they are the only mammal showing eusocial behavior, living in large colonies. Both male and female animals carry out communal tasks, live in colonies of up to 295 individuals, and restrict reproduction to one breeding female and 1 to 3 breeding males ${ }^{75}$. The natural habitat of naked mole rats are the hot, arid and semiarid regions of the northwestern Horn of Africa (Kenya, Ethiopia, and Somalia) where they maintain subterranean existence and rely on plant storage parts found below the ground for food ${ }^{77}$.

The most interesting feature of these rats is that they are resistant to age-linked diseases including cancer, diabetes, and most cardiovascular and neurological pathologies. Besides these, infectious diseases are also rare causes of death. Thus, in laboratory conditions, their mortality is very low and almost age independent ${ }^{78}$. The highest mortality rate observed in these rats is within the first 2 months of their life. The homeostatic balance with reference to body composition, basal metabolic rate, and gastrointestinal absorption are maintained for at least $70 \%$ of their impressive lifespan. They show only slight agerelated changes in all physiological and morphological characteristics. Interestingly, the breeding females show no decline in fertility even when well into their third decade of life ${ }^{79}$. The naked mole rats are highly tolerant to low oxygen and can sustain at, as low as, $3 \%$ oxygen. This hypoxia-tolerating characteristic may be connected with adaptation to chronic hypoxia associated with the burrowdwelling lifestyle ${ }^{80,81}$. The hypoxia-tolerating capacity in these animals is achieved through maintenance of high hematocrit value and hemoglobin levels with high oxygen affinities ${ }^{82}$.

The observations with respect to oxidative stress in naked mole rats are unusual and appear to challenge the Harman's oxidative stress theory of aging ${ }^{3}$. Contrary to the other laboratory rodents, these rats experience higher degree of oxidative stress and have been reported to exhibit three to eight fold higher levels of lipid peroxidation, carbonyls, and oxidative DNA damage relative to short lived mice ${ }^{83}$. However these results are in agreement with long-lived organisms including birds and bats ${ }^{84,85}$. The oxidative stress response of naked mole rats has been attributed to their long evolutionary background wherein they have adapted to hypoxic and hypercapnic environment. Furthermore, the cellular membrane of these animals exclusively contain a larger proportion of $n-6$ polyunsaturated fatty acids (PUFAs), including arachidonic acid whereas similar-sized rodents have membranes predominantly enriched with n-3 PUFA including docosahexaenoic acid ${ }^{86}$. This unique membrane composition does not change with age, suggesting that these rats are able to efficiently repair or remove damaged phospholipids. High levels of oxidative damage to all macromolecules suggest that these rats are capable of tolerating such damage throughout their long lives without any ill effect ${ }^{83,87}$.

Unlike other organisms, naked mole rats maintain low fasting blood glucose levels, but prolonged hyperglycemia in response to external glucose dose indicates some degree of insulin deficiency or resistance and reliance on alternative fuels such as fatty acids ${ }^{88,89}$. Moreover, these rats exhibit constitutively down-regulated components of insulin-signaling and mTOR pathways ${ }^{90}$. These characteristics may be attributed to their subterranean habitat with

Table 1. Lifespan and coding genes in aging model organisms: Comparison with human.

\begin{tabular}{|c|c|c|c|c|c|}
\hline Model organism & $\begin{array}{l}\text { Vertebrate/ } \\
\text { Invertebrate }\end{array}$ & Life span & $\begin{array}{l}\text { Number of protein } \\
\text { coding genes }\end{array}$ & Studied molecular pathways & Ref. \\
\hline Yeast & invertebrate & $1.5-3 \mathrm{~h}$ & $\sim 6000$ genes & $\begin{array}{l}\text { TOR, PKA, and Sch9 kinase } \\
\text { pathways }\end{array}$ & $18,22,23$ \\
\hline $\begin{array}{l}\text { Drosophila } \\
\text { melanogaster }\end{array}$ & invertebrate & $60-80$ days & $\sim 13600$ & IGF, mTORC, S6K & 38,39 \\
\hline C elegans (wild) & invertebrates & 11.8 days to 20 days & $\sim 19,099$ & $\begin{array}{l}\text { IIS, AMPK, TOR, SREBP } \\
\text { pathways }\end{array}$ & $55-57$ \\
\hline Rodents & vertebrates & $2-3$ years & $\begin{array}{l}\sim 23,317 \text { (mouse) } \\
\sim 22,841 \text { (rat) }\end{array}$ & mTORC1 pathway sirtuins ${ }^{7}$ & 71 \\
\hline Naked mole rat & vertebrates & 30 years & 22,561 & Nrf2, IGF1, mTOR & 106,107 \\
\hline $\begin{array}{l}\text { Birds (Fowl) } \\
\text { (Gallus gallus) }\end{array}$ & vertebrates & 30 years & $20,000-23,000$ & Ras-Erk-ETS-Signaling & 108 \\
\hline Human & vertebrates & 122 years $(\max )$ & $\sim 22,000$ & IGF, Sirtuins, mTOR & 109 \\
\hline
\end{tabular}


variable food availability. Low mTOR signaling is widely regarded as beneficial for extended longevity and may account for long lifespan in naked mole rats.

\section{Birds as model of aging}

"The rate-of-living hypothesis" was proposed a century ago based on general observation suggesting that metabolic rate is a key determinant of life expectancy of the given species ${ }^{26}$. Metabolic rate has a close relationship to body size. The greater the body size, the slower is the metabolic rate and cellular rate of $\mathrm{O}_{2}$ consumption and therefore the greater the lifespan ${ }^{91}$. However, avian aging does not obey this rule and it is remarkable that birds exhibit 3 times longer life span compared to the mammals of similar size ${ }^{92}$. The small humming bird and the migratory song birds are known to enjoy more than five years of life span in the wild and many species of wild seabirds exhibit survival of over 50 years. Paradoxically, some cockatoos in captivity are known to survive into their $60 \mathrm{~s}^{93,94}$. Besides these, certain birds such as Northern fulmar (Fulmarus glacialis), is even reported to age more slowly than humans ${ }^{95}$. Although, birds exhibit a marked difference in life span compared to mammals, they carry similar traits of aging associated diseases observed for the mammals including cardiovascular disease, cancers, cataracts, osteoarthritis and diabetes. However, they show delayed progression of such pathologies which correlate with their rate of aging ${ }^{94}$.

A closer insight into the general physiological traits of birds is in contrast to their unusual longevity. Compared to mammals, birds have been reported to exhibit about 3 ${ }^{\circ} \mathrm{C}$ higher body temperature and several fold higher blood glucose concentrations which favors higher degree of protein glycol-oxidation ${ }^{94,96}$. The higher metabolic rates of avian species are expected to generate excessive reactive oxygen species that could impose higher level of oxidative damage ${ }^{97}$. Moreover migratory birds exhibit exceptional flight endurance of up to $200 \mathrm{~h}$ non-stop, at a very high metabolic rate while fasting. Contrary to this notion, studies involving isolated mitochondria show lower ROS generation in birds per unit of $\mathrm{O}_{2}$ consumption compared to mammals of equal size ${ }^{98,99}$. The observed lower ROS generation has been attributed to reduced activity of complex I of the electron transport chain which is the major site of superoxide anion formation. Furthermore, the in vitro studies involving renal epithelial cell and the fibroblast lineage from long lived birds species suggest that they are more resistant towards oxidative stress and DNA damaging agents compared to the mouse cell lines ${ }^{100,101}$. Cultured avian cells seem to be more effective than mammalian cells at resisting oxidative stresses of various kinds, and this resistance appears to require active DNA transcription $^{94}$.

There is also evidence that membranes in bird tissues contain less unsaturated lipid than those in rodent tissues $^{102}$. This might lead to greater resistance to lipid peroxidation, one of the key processes among ROS induced oxidative damage. Another fact is that birds are uricotelic animals and possess raised levels of urates (salts of uric acid) in blood. These salts, being natural antioxidants, can contribute to the body's defense against ROS (ref. ${ }^{103}$ ). This property of birds show marked similarity with Hominoid primates. Humans with exceptional longevity also have evolved a mutation in the urate oxidase (uricase) gene, however such mutation is absent in other mammals ${ }^{104,105}$.

\section{CONCLUSION}

The complexity of human aging necessitate further research to reveal the underlying causes, however the feasibility of human as model of aging research remain provocative particularly due to ethical issues, longer lifespan and issues governing control variables. Thus, alternate animal model systems provide important tool for aging research. Although vast diversity exists among the various models, at molecular level these model systems share the common pathways and the invertebrate models including yeast, worm and flies provide much contribution in dissecting these pathways. Additionally certain organisms such as naked mole rats which demonstrate exceptional lifespan exhibit certain peculiar characteristics including low blood sugar with maximum energy demand met by fatty acid oxidation. These features have been assumed to be evolutionarily acquired as adaptation toward their survival in hypoxic and hypercapnic environment.

The discovery of TOR pathway which is modulated by an abundance of nutrient has been found to have been evolved universally across the biological system and the activity of this pathway plays a major influence on life span of organisms. Since rodents show more proximity to humans with reference to anatomy and physiology, they have been model of choice for aging research.

\section{Search strategy and selection criteria}

The literature for this review was collected after extensive search on PUBMED. Initially the search was undertaken with general terms: model+aging. Through a thorough perusal of the available literature we could narrow down the list of organisms to be potential candidates for inclusion in this review. Once the decision to include yeast, Drosophila, C. elegans, rodents, naked mole rat, and birds was achieved, we undertook search on PUBMED with specific key words. Overall there exists a huge amount of literature on each model of aging which we shortlisted. Our strategy to include information, which we have presented in this review, was dictated by the relative importance of the report/finding with respect to current understanding of aging and lifespan.

Acknowledgement: SIR acknowledges the support of Department of Science and Technology, SERB grant (EMR/2016/006470) in the form a major research project. NAM S\&T Centre, New Delhi is acknowledged for providing financial support to MKC, Assistant Professor, Department of Biochemistry, Janaki Medical College and Teaching Hospital, Ramdaiya, Bhawadi, Nepal, in the form of "Research Training Fellowship for Developing Country Scientists (RTF-DCS)”. 
Author contributions: MKC: literature search, manuscript writing; SIR: manuscript writing and presentation in final form.

\section{REFERENCES}

1. Swartz A. James Fries. Healthy Aging Pioneer. Am J Public Health 2008;98(7):1163-6.

2. Carvalhal Marques F, Volovik Y, Cohen E. The Roles of Cellular and Organismal Aging in the Development of Late-Onset Maladies. Annu Rev Pathol 2015;10:1-23.

3. Harman D. Free Radical Theory of Aging: An Update: Increasing the Functional Life Span. Ann N Y Acad Sci 2006;1067:10-21.

4. López-Otín C, Blasco MA, Partridge L, Serrano M, Kroemer G. The Hallmarks of Aging. Cell 2013;153(6):1194-217.

5. Von Zglinicki T. Oxidative stress shortens telomeres. Trends Biochem Sci 2002;27(7):339-44.

6. Goldsmith TC. The evolution of aging: how new theories will change the future of medicine.3rd ed. Crownsville, Azinet Press; 2014.

7. Colman RJ, Anderson RM, Johnson SC, Kastman EK, Kosmatka KJ, Beasley TM, Allison DB, Cruzen C, Simmons HA, Kemnitz JW, Weindruch R. Caloric Restriction Delays Disease Onset and Mortality in Rhesus Monkeys. Science 2009;325(5937):201-4.

8. Schaible R, Scheuerlein A, Dańko MJ, Gampe J, Martínez DE, Vaupel JW. Constant Mortality and Fertility Over Age in Hydra. Proc Natl Acad Sci 2015;112(51):15701-6.

9. Klapper W, Kühne K, Singh KK, Heidorn K, Parwaresch R, Krupp G. Longevity of lobsters is linked to ubiquitous telomerase expression. FEBS Lett 1998;439(1-2):143-6.

10. Karathia H, Vilaprinyo $E$, Sorribas A, Alves R. Saccharomyces cerevisiae as a Model Organism: A Comparative Study. PLoS ONE. 2011;6(2):e16015.

11. Gershon H, Gershon D. The budding yeast, Saccharomyces cerevisiae, as a Model for Aging Research: a critical review. Mech Ageing Dev 2000;120(1-3):1-22.

12. Laurent JM, Young JH, Kachroo AH, Marcotte EM. Efforts to make and apply humanized yeast. Brief Funct Genomics 2016;15(2):155-63.

13. Mortimer RK, Johnston JR. Life Span of Individual Yeast Cells. Nature 1959;183(4677):1751-2.

14. Mirisola MG, Braun RJ, Petranovic D. Approaches to study yeast cell aging and death. FEMS Yeast Res 2014;14(1):109-18.

15. Longo VD, Fabrizio P. Chronological aging in Saccharomyces cerevisiae. Subcell Biochem 2012;57:101-21.

16. Lin SJ, Defossez PA, Guarente L. Requirement of NAD and SIR2 for life-span extension by calorie restriction in Saccharomyces cerevisiae. Science 2000;289(5487):2126-8.

17. Lin S-J, Kaeberlein M, Andalis AA, Sturtz LA, Defossez P-A, Culotta VC Fink GR, Guarente L. Calorie restriction extends Saccharomyces cerevisiae lifespan by increasing respiration. Nature 2002;418(6895):344 8.

18. Powers RW. Extension of chronological life span in yeast by decreased TOR pathway signaling. Genes Dev 2006;20(2):174-84.

19. Kaeberlein M. Regulation of Yeast Replicative Life Span by TOR and Sch9 in Response to Nutrients. Science. 2005;310(5751):1193-6.

20. Kapahi P, Chen D, Rogers AN, Katewa SD, Li PW-L, Thomas EL, Kockel L. With TOR, Less Is More: A Key Role for the Conserved NutrientSensing TOR Pathway in Aging. Cell Metab 2010;11(6):453-65.

21. Fabrizio P, Pletcher SD, Minois N, Vaupel JW, Longo VD. Chronological aging-independent replicative life span regulation by Msn2/Msn4 and Sod2 in Saccharomyces cerevisiae. FEBS Lett 2004;557(1-3):136 42.

22. Longo VD. The Ras and Sch9 pathways regulate stress resistance and longevity. Exp Gerontol 2003;38(7):807-11.

23. Roosen J, Engelen K, Marchal K, Mathys J, Griffioen G, Cameroni E, Thevelein JM, De Virgilio C, De Moor B, Winderickx J. PKA and Sch9 control a molecular switch important for the proper adaptation to nutrient availability: CAMP-gating in yeast. Mol Microbiol 2004;55(3):862-80.

24. Tenreiro S, Outeiro TF. Simple is good: yeast models of neurodegeneration: Yeast as a model for neurodegeneration. FEMS Yeast Res 2010;10(8):970-9.
25. Botstein D, Fink GR. Yeast: An Experimental Organism for 21st Century Biology. Genetics 2011;189(3):695-704.

26. Finkel T, Holbrook NJ. Oxidants, oxidative stress and the biology of ageing. Nature 2000;408(6809):239-47.

27. Herrero E, Ros J, Bellí G, Cabiscol E. Redox control and oxidative stress in yeast cells. Biochim Biophys Acta 2008;1780(11):1217-35.

28. Hofer S, Kainz K, Zimmermann A, Bauer MA, Pendl T, Poglitsch M, Madeo F, Carmona-Gutierrez D. Studying Huntington's Disease in Yeast: From Mechanisms to Pharmacological Approaches. Front Mol Neurosc 2018;11:318.

29. Morgan TH. Sex limited inheritance in drosophila. Science. 1910;32(812):120-2.

30. Reiter LT. A Systematic Analysis of Human Disease-Associated Gene Sequences In Drosophila melanogaster. Genome Res 2001;11(6):1114-25.

31. Adams MD. The Genome Sequence of Drosophila melanogaster. Science 2000;287(5461):2185-95.

32. Matthews KA, Kaufman TC, Gelbart WM. Research resources for Drosophila: the expanding universe. Nat Rev Genet 2005;6(3):17993.

33. Bernards A, Hariharan IK. Of flies and men--studying human disease in Drosophila. Curr Opin Genet Dev. 2001;11(3):274-8.

34. Tower J, Arbeitman M. The genetics of gender and life span. J. Biology 2009;8(4):38.

35. Musselman LP, Fink JL, Ramachandran PV, Patterson BW, Okunade AL, Maier E, Brent MR, Turk J, Baranski TJ. Role of Fat Body Lipogenesis in Protection against the Effects of Caloric Overload in Drosophila. J. Biol. Chem 2013;288(12):8028-42.

36. Waskar M, Li Y, Tower J. Stem cell aging in the Drosophila ovary. AGE 2005;27(3):201-12.

37. He $\mathrm{Y}$, Jasper $\mathrm{H}$. Studying aging in Drosophila. Methods 2014;68(1):129-33.

38. Clancy DJ. Extension of Life-Span by Loss of CHICO, a Drosophila Insulin Receptor Substrate Protein. Science 2001;292(5514):104-6.

39. Bjedov I, Toivonen JM, Kerr F, Slack C, Jacobson J, Foley A, Partridge L. Mechanisms of Life Span Extension by Rapamycin in the Fruit Fly Drosophila melanogaster. Cell Metab 2010;11(1):35-46.

40. Fiorino A, Thompson D, Yadlapalli S, Jiang C, Shafer OT, Reddy P, Meyhofer E. Parallelized, real-time, metabolic-rate measurements from individual Drosophila. Sci Rep 2018;8(1)14452.

41. De Nobrega AK, Lyons LC. Aging and the clock: Perspective from flies to humans. Eur J Neurosci 2018 Oct 30. [Epub ahead of print] doi: $10.1111 /$ ejn.14176

42. Orr W, Sohal R. Extension of life-span by overexpression of superoxide dismutase and catalase in Drosophila melanogaster. Science 1994;263(5150):1128-30.

43. Kubiak M, Tinsley MC. Sex-Specific Routes To Immune Senescence In Drosophila melanogaster. Sci Rep. 2017;7(1):10417. doi: 10.1038/ s41598-017-11021-6

44. Felix TM, Hughes KA, Stone EA, Drnevich JM, Leips J. Age-Specific Variation in Immune Response in Drosophila melanogaster Has a Genetic Basis. Genetics 2012;191(3):989-1002.

45. Klass M, Hirsh D. Non-ageing developmental variant of Caenorhabditis elegans. Nature 1976;260(5551):523-5.

46. Morris JZ, Tissenbaum HA, Ruvkun G. A phosphatidylinositol3-OH kinase family member regulating longevity and diapause in Caenorhabditis elegans. Nature 1996;382(6591):536-9.

47. C. elegans Sequencing Consortium. Genome sequence of the nematode $C$. elegans: a platform for investigating biology. Science 1998;282(5396):2012-8.

48. Kamath RS, Fraser AG, Dong Y, Poulin G, Durbin R, Gotta M, Kanapin A, Le Bot N, Moreno S, Sohrmann M, Welchman DP, Zipperlen P, Ahringer J. Systematic functional analysis of the Caenorhabditis elegans genome using RNAi. Nature 2003;421(6920):231-7.

49. Lee SS, Lee RYN, Fraser AG, Kamath RS, Ahringer J, Ruvkun G. A systematic RNAi screen identifies a critical role for mitochondria in C. elegans longevity. Nat Genet. 2003;33(1):40-8.

50. Herndon LA, Schmeissner PJ, Dudaronek JM, Brown PA, Listner KM, Sakano Y, Paupard MC, Hall DH, Driscoll M. Stochastic and genetic factors influence tissue-specific decline in ageing $C$. elegans. Nature 2002;419(6909):808-14.

51. Adachi H, Fujiwara $Y$, Ishii N. Effects of oxygen on protein carbonyl and aging in Caenorhabditis elegans mutants with long 
(age-1) and short (mev-1) life spans. J Gerontol A Biol Sci Med Sci 1998;53(4):B240-4.

52. Fielenbach N, Antebi A. C. elegans dauer formation and the molecular basis of plasticity. Genes Dev 2008;22(16):2149-65.

53. Collins JJ, Huang C, Hughes S, Kornfeld K. The measurement and analysis of age-related changes in Caenorhabditis elegans. WormBook 2008;1-21.

54. Altintas O, Park S, Lee S-JV. The role of insulin/IGF-1 signaling in the longevity of model invertebrates, C. elegans and D. melanogaster. BMB Rep 2016;49(2):81-92.

55. Zheng J, Greenway FL. Caenorhabditis elegans as a model for obesity research. Int J Obes (Lond) 2012;36(2):186-94.

56. Lapierre LR, Hansen M. Lessons from C. elegans: signaling pathways for longevity. Trends Endocrinol Metab 2012;23(12):637-44.

57. Lee D, Jeong D-E, Son HG, Yamaoka Y, Kim H, Seo K, Khan AA, Roh T-Y, Moon DW, Lee Y, Lee S-JV. SREBP and MDT-15 protect C. elegans from glucose-induced accelerated aging by preventing accumulation of saturated fat. Genes Dev 2015;29(23):2490-503.

58. Dutta S, Sengupta P. Men and mice: Relating their ages. Life Sci 2016;152:244-8.

59. Sengupta P. The Laboratory Rat: Relating Its Age With Human's. Int J Prev Med 2013;4(6):624-30.

60. Vanhooren $V$, Libert $C$. The mouse as a model organism in aging research: Usefulness, pitfalls and possibilities. Ageing Res Rev 2013;12(1):8-21.

61. Mestas J, Hughes CCW. Of Mice and Not Men: Differences between Mouse and Human Immunology. J Immunol 2004;172(5):2731-8.

62. Demetrius L. Of mice and men. EMBO Rep 2005;6(Suppl 1):S39-S44

63. Hasty $\mathrm{P}, \mathrm{Vijg}$ J. Accelerating aging by mouse reverse genetics: a rational approach to understanding longevity. Aging Cell 2004;3(2):55 65.

64. Mitchell SJ, Scheibye-Knudsen M, Longo DL, De Cabo R. Animal Models of Aging Research: Implications for Human Aging and AgeRelated Diseases. Annu Rev Anim Biosci. 2015:3(1):283-303.

65. Bogue MA, Peters LL, Paigen B, Korstanje R, Yuan R, Ackert-Bicknell C, Grubb SC, Churchill GA, Chesler EJ. Accessing Data Resources in the Mouse Phenome Database for Genetic Analysis of Murine Life Span and Health Span. J Gerontol A Biol Sci Med Sci 2016;71(2):170-7.

66. Eppig JT, Richardson JE, Kadin JA, Ringwald M, Blake JA, Bult CJ. Mouse Genome Informatics (MGI): reflecting on 25 years. Mamm Genome 2015;26(7-8):272-84.

67. Tremblay M-Ë, Zettel ML, Ison JR, Allen PD, Majewska AK. Effects of aging and sensory loss on glial cells in mouse visual and auditory cortices. Glia 2012;60(4):541-58.

68. Ward JM. Lymphomas and leukemias in mice. Exp Toxicol Pathol 2006;57(5-6):377-81.

69. Harrison DE, Strong R, Sharp ZD, Nelson JF, Astle CM, Flurkey K, Nadon NL, Wilkinson JE, Frenkel K, Carter CS, Pahor M, Javors MA, Fernandez E, Miller RA. Rapamycin fed late in life extends lifespan in genetically heterogeneous mice. Nature 2009;460(7253):392-5.

70. Folgueras AR, Freitas-Rodríguez S, Velasco G, López-Otín C. Mouse Models to Disentangle the Hallmarks of Human Aging. Circ Res 2018;123(7):905-24.

71. Cox LS, Mattison JA. Increasing longevity through caloric restriction or rapamycin feeding in mammals: common mechanisms for common outcomes? Aging Cell 2009;8(5):607-13.

72. Williams K, Roman J. Studying human respiratory disease in animals - role of induced and naturally occurring models: Modelling respiratory disease in animals. J Pathol 2016;238(2):220-32.

73. Gong B, Levine S, Barnum SR, Pasinetti GM. Role of complement systems in IVIG mediated attenuation of cognitive deterioration in Alzheimer's disease. Curr Alzheimer Res 2014;11(7):637-44.

74. Kudlow BA, Kennedy BK, Monnat RJ. Werner and Hutchinson-Gilford progeria syndromes: mechanistic basis of human progeroid diseases.Nat Rev Mol Cell Biol 2007;8(5):394-404.

75. Lewis KN, Buffenstein R. The Naked Mole-Rat. eLife 2018;7:e31157.

76. Edrey YH, Hanes M, Pinto M, Mele J, Buffenstein R. Successful aging and sustained good health in the naked mole rat: a long-lived mammalian model for biogerontology and biomedical research. ILAR J 2011;52(1):41-53.

77. Sherman PW, Jennifer U M Jarvis, Richard D. Alexander, editors. The Biology of the Naked Mole-Rat. New Jersey: Princeton University Press; 1991 .

78. Buffenstein R. The Naked Mole-Rat: A New Long-Living Model for Human Aging Research. J Gerontol A Biol Sci Med Sci 2005;60(11):1369-77.

79. Buffenstein R. Negligible senescence in the longest living rodent, the naked mole-rat: insights from a successfully aging species. J Comp Physiol B 2008;178(4):439-45

80. Nathaniel TI, Saras A, Umesiri FE, Olajuyigbe F. Tolerance to oxygen nutrient deprivation in the hippocampal slices of the naked mole rats. J Integr Neurosci 2009;8(2):123-36.

81. Frappell PB, Mortola JP. Hamsters vs. rats: metabolic and ventilatory response to development in chronic hypoxia. J Appl Physiol 1994;77(6):2748-52.

82. Buffenstein R, Woodley R, Thomadakis C, Daly TJM, Gray DA. Coldinduced changes in thyroid function in a poikilothermic mammal, the naked mole-rat. Am J Physiol Regul Integr Comp Physiol 2001;280(1):R149-55.

83. Andziak B, Buffenstein R. Disparate patterns of age-related changes in lipid peroxidation in long-lived naked mole-rats and shorter-lived mice. Aging Cell 2006;5(6):525-32.

84. Brunet Rossinni AK. Testing the Free Radical Theory of Aging in Bats. Ann N Y Acad Sci 2004;1019:506-8.

85. Perez-Campo R, López-Torres M, Cadenas S, Rojas C, Barja G. The rate of free radical production as a determinant of the rate of aging: evidence from the comparative approach. J Comp Physiol B 1998;168(3):149-58

86. Hulbert AJ, Faulks SC, Buffenstein R. Oxidation-Resistant Membrane Phospholipids Can Explain Longevity Differences Among the Longest-Living Rodents and Similarly-Sized Mice. J Gerontol A Biol Sci Med Sci 2006;61(10):1009-18.

87. Perez VI, Buffenstein R, Masamsetti V, Leonard S, Salmon AB, Mele J, Andziak B, Yang T, Edrey Y, Friguet B, Ward W, Richardson A, Chaudhuri A. Protein stability and resistance to oxidative stress are determinants of longevity in the longest-living rodent, the naked mole-rat. Proc Natl Acad Sci U S A 2009;106(9):3059-64.

88. Kramer B, Buffenstein R. The pancreas of the naked mole-rat (Heterocephalus glaber): an ultrastructural and immunocytochemical study of the endocrine component of thermoneutral and cold acclimated animals. Gen Comp Endocrinol 2004;139(3):206-14.

89. Buffenstein R, Yahav $S$. The effect of diet on microfaunal population and function in the caecum of a subterranean naked mole-rat Heterocephalus glaber. Br J Nutr 1991;65(2):249-58.

90. Kim EB, Fang X, Fushan AA, Huang Z, Lobanov AV, Han L, Marino SM Sun X, Turanov AA, Yang P, Yim SH, Zhao X, Kasaikina MV, Stoletzki N, Peng C, Polak P, Xiong Z, Kiezun A, Zhu Y, Chen Y, Kryukov GV, Zhang Q, Peshkin L, Yang L, Bronson RT, Buffenstein R, Wang B, Han C, Li Q, Chen L, Zhao W, Sunyaev SR, Park TJ, Zhang G, Wang J, Gladyshev VN. Genome sequencing reveals insights into physiology and longevity of the naked mole rat. Nature 2011:479(7372):223-7.

91. Calder WA. Size, function, and life history. Mineola, New York: Dover Publications; 1996

92. Austad, Steven N. 2011. "Candidate bird species for use in aging research." ILAR journal 52 (1):89-96.

93. Brouwer K, Jones $M L$, King CE, Schifter $\mathrm{H}$. Longevity records for Psittaciformes in captivity. International Zoo Yearbook 2000;37(1):299-316

94. Holmes D., Ottinger M. Birds as long-lived animal models for the study of aging. Exp Gerontol 2003;38(11-12):1365-75.

95. Gosden RG. Cheating time: science, sex, and aging. New York:W.H. Freeman; 1996

96. Harrison GJ, Harrison LR. Clinical avian medicine and surgery: incl. aviculture. Philadelphia;1986.

97. Furness LJ, Speakman JR. Energetics and longevity in birds. Age 2008;30(2-3):75-87.

98. Lambert AJ, Boysen HM, Buckingham JA, Yang T, Podlutsky A, Austad $\mathrm{SN}$, Kunz TH, Buffenstein R, Brand MD. Low rates of hydrogen peroxide production by isolated heart mitochondria associate with long maximum lifespan in vertebrate homeotherms. Aging Cell 2007:6(5):607-18.

99. Barja G, Cadenas S, Rojas C, Pérez-Campo R, López-Torres M. Low mitochondrial free radical production per unit $\mathrm{O} 2$ consumption can explain the simultaneous presence of high longevity and high aerobic metabolic rate in birds. Free Radic Res 1994:21(5):317-27.

100. Ogburn CE, Carlberg K, Ottinger MA, Holmes DJ, Martin GM, Austad SN. Exceptional Cellular Resistance to Oxidative Damage in LongLived Birds Requires Active Gene Expression. J Gerontol A Biol Sci Med Sci 2001;56(11):B468-74. 
101. Harper JM, Wang M, Galecki AT, Ro J, Williams JB, Miller RA. Fibroblasts from long-lived bird species are resistant to multiple forms of stress. J Exp Biol 2011;214(11):1902-10.

102. Pamplona R, Portero-Otín M, Riba D, Ledo F, Gredilla R, Herrero A, Barja G. Heart fatty acid unsaturation and lipid peroxidation, and aging rate, are lower in the canary and the parakeet than in the mouse. Aging (Milano) 1999;11(1):44-9.

103. Hickey AJR, Jüllig M, Aitken J, Loomes K, Hauber ME, Phillips ARJ. Birds and longevity: Does flight driven aerobicity provide an oxidative sink? Ageing Res Rev 2012;11(2):242-53.

104. Wu XW, Muzny DM, Lee CC, Caskey CT. Two independent mutational events in the loss of urate oxidase during hominoid evolution. J Mol Evol 1992;34(1):78-84.

105. Tsahar E, Arad Z, Izhaki I, Guglielmo CG. The relationship between uric acid and its oxidative product allantoin: a potential indica- tor for the evaluation of oxidative stress in birds. J Comp Physiol B. 2006;176(7):653-61.

106. Sahm A, Bens M, Szafranski K, Holtze S, Groth M, Görlach M, Calkhoven C, Müller C, Schwab M, Kraus J, Kestler HA, Cellerino A, Burda H, Hildebrandt T, Dammann P, Platzer M. Long-lived rodents reveal signatures of positive selection in genes associated with lifespan. PLoS Genet 2018;14(3):e1007272.

107. Lewis KN, Mele J, Hornsby PJ, Buffenstein R. Stress Resistance in the Naked Mole-Rat: The Bare Essentials-A Mini-Review. Gerontology 2012;58(5):453-62.

108. Elbourkadi N, Austad SN, Miller RA. Fibroblasts from long-lived species of mammals and birds show delayed, but prolonged, phosphorylation of ERK. Aging Cell 2014;13(2):283-91.

109. Pan H, Finkel T. Key proteins and pathways that regulate lifespan. J Biol Chem 2017;292(16):6452-60. 